\title{
STUDI BIOLOGI DAN BUDAYA MASYARAKAT PESISIR PANTAI DI SUMENEP (KAJIAN ETNOBIOLOGI PASAR TRADISIONAL PENGGIR PAPAS)
}

Fadhlan Muchlas Abrori1*

1Universitas Borneo Tarakan, Jl. Amal Lama No. 1, Tarakan 77115, Indonesia

*Corresponding author, e-mail : fadhlan1991@gmail.com

\section{ABSTRACT}

Coastal communities in Sumenep area have a peculiarity in selling seafood to consumers. Generally, fish catchers (sailor) will immediately sell their catch fish in the early hours on the seafront that called penggir papas market. The study was conducted in 3 sub-districts in the Sumenep area located in the coastal area. Data obtained were analyzed descriptively which included: Relative Frequency of Citation, Fidelity Level, and IUCN Status. Based on data collection related to commodity species in the penggir papas market in Sumenep area, there were 24 species. The list of species is grouped into 2 types based on their kingdom namely: Animalia (88\%) and Protista (22\%). There are 5 species in group I (low interest and low preference), 1 species in group II (high interest and low preference), 1 species in group III (low interest and high preference) and 17 species in group IV (high importance and preference high).Data related to IUCN status are at least $63 \%$ of species that have not been evaluated, $4 \%$ including endangered, $12 \%$ near threatened, $8 \%$ least concern and $13 \%$ data deficient.

Keywords: Ethnobiology, Penggir Papas Market, Commodity Species

\section{PENDAHULUAN}

Indonesia merupakan negara tropis yang memiliki keunikan sebagai negara kepulauan yang mengandalkan hasil laut sebagai salah satu komoditi utamanya. Durand (2010) menyatakan bahwa Indonesia terdiri dari sekitar 17.504 pulau, dengan garis pantai secara keseluruhan mencapai sekitar $95.181 \mathrm{~km}$. Berdasarkan kondisi Indonesia sebagai negara kepulauan, sekitar 60\% penduduk Indonesia hidup di daerah pesisir.

Sumenep merupakan salah satu kabupaten di Indonesia yang memiliki kawasan pesisir yang luas. Berdasarkan data dari BAPPEDA JATIM (2013) Kabupaten Sumenep memiliki luas wilayah sebesar 2.093,458 $\mathrm{km}^{2}$ yang terbagi menjadi 27 kecamatan, 328 desa dan 4 kelurahan. Secara geografis sumenep terbagi menjadi 2 wilayah, yaitu: daratan dan kepulauan. Wilayah daratan di Sumenep memiliki luas 1.146,927 Km2 (54,79\%) dan wilayah kepulauan memiliki luas 946,531 $\mathrm{Km} 2(45,21 \%)$.

Masyarakat pesisir di daerah Sumenep memiliki kekhasan dalam menjual hasil laut kepada konsumen. Umumnya penangkap ikan akan langsung menjual ikan hasil tangkapannya pada dini hari di pinggir laut. Berdasarkan kegiatan jual beli secara langsung di pinggir laut antara nelayan dan konsumen, maka kegiatan jual beli ini dinamakan pasar penggir papas. Pasar penggir papas secara etimologi merupakan pasar yang ada di pinggir pesisir. Kegiatan ini umumnya terjadi dan menjadi tradisi pada beberapa daerah pesisir di Sumenep.

Hasil laut yang dijual pada pasar penggir papas umumnya bervariasi mulai dari jenis alga (rumput laut pada marga Gelidium, Gracilaria, Eucheuma, dan 
Sargassum), arthropoda, moluska dan pisces (ikan-ikanan). Bervariasinya jenis hasil laut terkadang ada beberapa jenis yang merupakan hewan yang memiliki status vulnerable (rentan) berdasarkan kategori IUCN. Berdasarkan data dari Ubaidillah et al., (2013) dan Nezon (2011) didapatkan data setidaknya terdapat 78 jenis biota laut yang merupakan spesies prioritas yang terdiri dari 19.23\% pisces, $6.41 \%$ mamalia, $17.9 \%$ reptil, $12.82 \%$ moluska, $33.33 \%$ echinodermata, $5,12 \%$ coelenterate, dan $1,28 \%$ crustacea.

Penelitian ini memberikan gambaran secara menyeluruh terkait jenis-jenis tumbuhan dan hewan yang dijadikan komoditi dalam kegiatan jual beli di Pasar penggir papas. Hasil penelitian ini memberikan gambaran terkait status konservasi jenis-jenis tumbuhan dan hewan komoditi, sehingga nantinya diharapkan pemerintah daerah mampu memberikan sosialisasi terkait konservasi tumbuhan atau hewan yang yang memiliki status rentan. Hasil penelitian juga diharapkan memberikan wawasan baru untuk menjaga jenis rentan berdasarkan IUCN agar tidak dijadikan sebagai komoditi jual beli.

\section{METODE}

\section{Area Pengambilan Data}

Penelitian dilakukan pada 3 kecamatan di daerah Sumenep yang berada pada daerah pesisir. Kecamatan tempat dilaksanakan pengambilan data adalah kecamatan Ambunten, Kecamatan Kebun Dadap, dan Kecamatan Prenduan (Gambar 1).

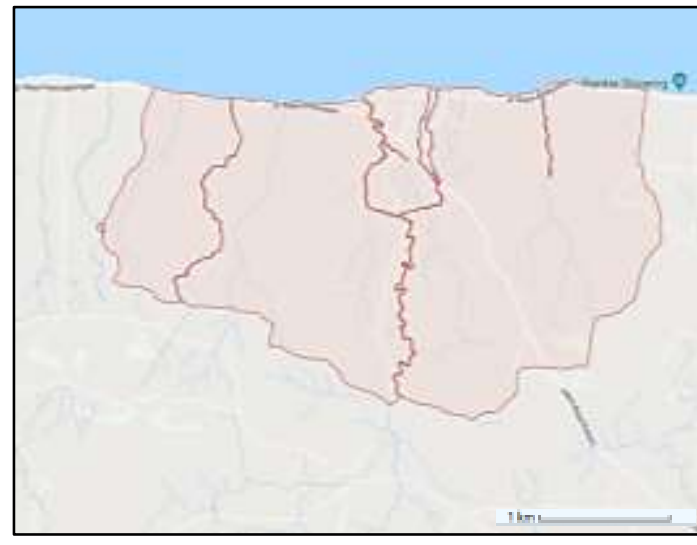

(a)

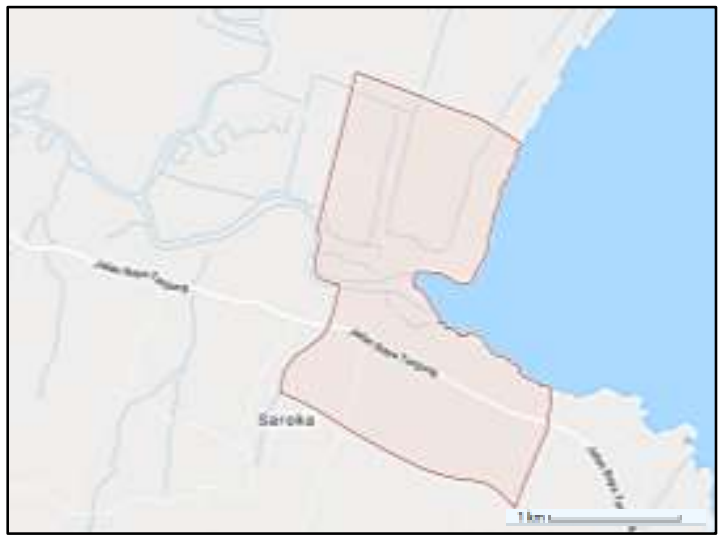

(b)

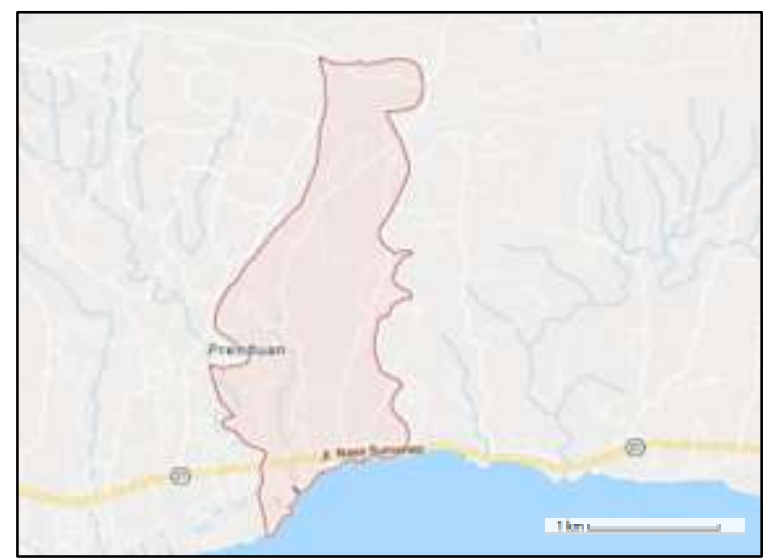

Gambar 1. Area Pengambilan Data : (a) Kecamatan Ambunten; (b) Kecamatan Kebun Dadap; dan (c) Kecamatan Prenduan 


\section{Pengumpulan Data}

Survei lapangan dilaksanakan pada tanggal 1 Februari sampai 15 Februari 2018. Data yang dikumpulkan terkait spesies yang dijadikan komoditi jual beli pada pasar penggir papas menggunakan metode participatory rural apparaisal (PRA) yang mengacu kepada Kim dan Song (2011); Huntington (2000); Alexiandes (1996), Theis dan Grady (1991); Long dan Wang (1996); Martin (2007) dimana para informan juga dapat bertindak sebagai penyidik. Pada pengumpulan data juga terdapat adanya wawancara, pertemuan informal, diskusi terbuka, diskusi kelompok dan pengisian kuesioner semi-terstruktur.

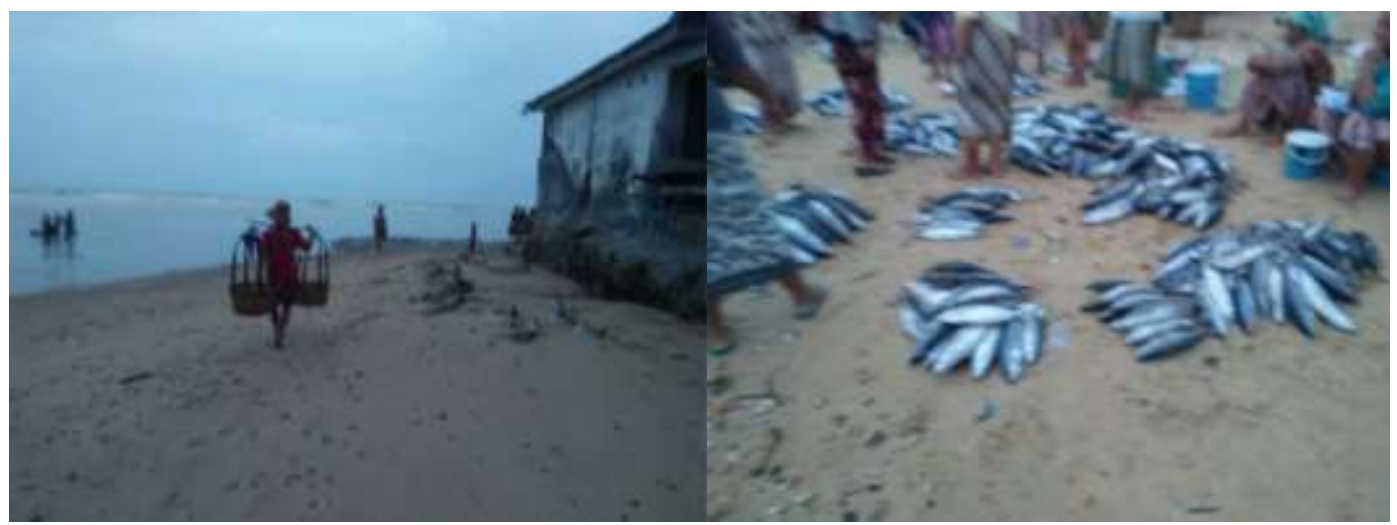

Gambar 2. Kondisi Kegiatan Jual Beli di Pasar Penggir Papas

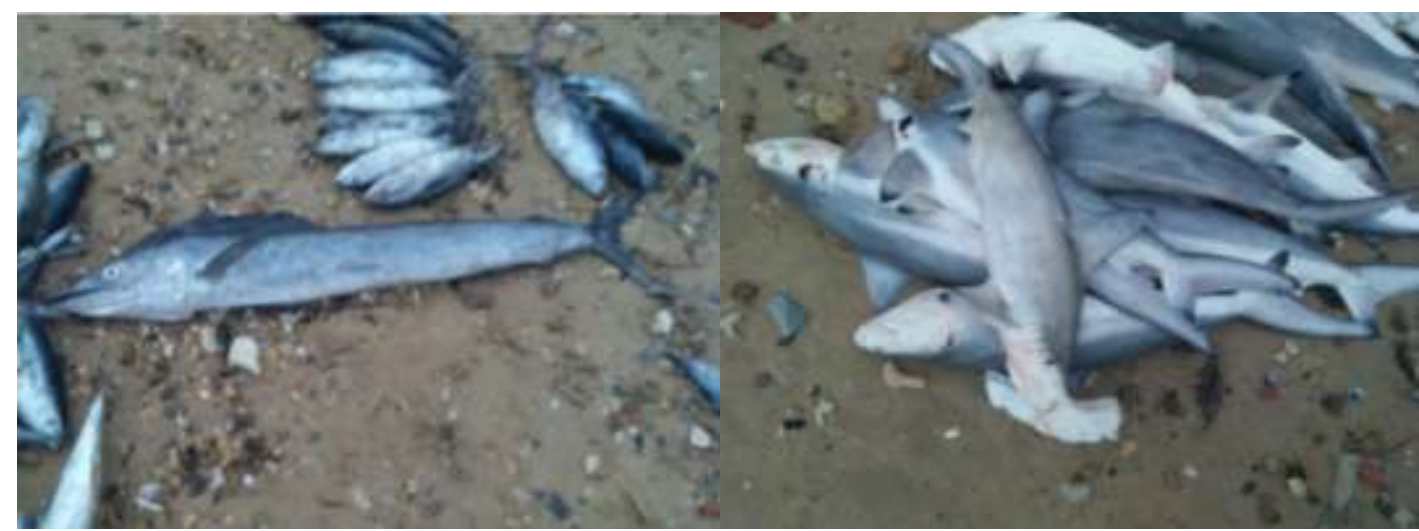

a.

b.

Gambar 3. Spesies komoditi di pasar Penggir Papas. a) Makaira indica Cuvier; b)

Carcharhinus leucas Müller \& Henle. dan Sphyrna lewini Grifftih \& Smith.

Perincian data dari informan menggunakan kuesioner semi-terstruktur yang mencakup beberapa hal terkait spesies komoditi jual beli, yaitu: nama lokal spesies, bagian yang digunakan, manfaat, serta teknik pengolahan spesies dalam kehidupan sehari-hari. Usia informan bervariasi mulai dari usia 20 sampai 60 tahun.

Informan dalam penelitian ini adalah semua lapisan masyarakat yang terlibat dalam proses jual beli di pasar penggir papas. Secara garis besar informan dikelompokkan menjadi nelayan, distributor/penadah, dan pembeli. Teknik sampling dalam penelitian ini menggunakan teknik sampling kombinasi, melalui snowball sampling dan sampling kuota. Pemilihan sampel untuk setiap kelompok informan (nelayan, distributor/penadah, dan pembeli) dimulai dari 1 orang tiap kelompok, kemudian 1 orang tersebut merekomendasikan 2-3 orang dan seterusnya sampai 
mencapai 15 orang untuk setiap kelompok (pada setiap kecamatan diwakili oleh 5 orang nelayan, 5 orang penadah dan 5 orang pembeli). Jumlah keseluruhan informan adalah 45 orang.

\section{Perhitungan Frekuensi Sitasi Relatif (Relative Frequency of Citation)}

Frekuensi sitasi relative (Relative frequency of Citation) atau disingkat RFC mengacu kepada Vitalini et al. (2012); Mootsamydan Mahomoodly (2014); Borah dan Prasad (2017) yang menunjukkan kepentingan lokal setiap spesies. Nilai RFC dikalibarsi dengan rumus:

$$
\mathrm{RFC}=\frac{\mathrm{FC}}{\mathrm{N}}
$$

Keterangan

$\mathrm{FC} \quad=$ jumlah informan yang menyebutkan tentang penggunaan spesies

$\mathrm{N} \quad=$ jumlah informan yang berpartisipasi dalam survey.

Indeks RFC bervariasi dari 0 hingga 1 . Ketika indeks RFC menunjukkan angka 0 berarti tidak ada informan yang memanfaatkan spesies tersebut, ketika nilai indek RFC menunjukkan nilai 1 menunjukkan semua informan menggunakan spesies tersebut.

\section{Perhitungan Tingkat Kesetiaan/ Kesukaan (Fidelity Level)}

Tingkat kesetiaan/ kesukaan (fidelity level) atau disebut FL dihitung untuk menentukan spesies yang memiliki tingkat kepentingan tertinggi terutama yang digunakan untuk pangan pada kehidupan sehari-hari informan. Perhitungan FL mengacu kepada Friedmen et al., (1986) dengan rumus sebagai berikut:

Keterangan

$$
\text { FL }(\%)=\operatorname{Np} \times \frac{100}{N}
$$

$\mathrm{Np} \quad=$ jumlah informan yang mengklaim penggunaan spesies untuk pangan/ kegunaan pangan tertentu yang dianggap penting

$\mathrm{N} \quad=$ jumlah total informan yang memberikan informasi spesies

\section{Status International Union for Conservation of Nature and Natural Resources (IUCN)}

Status IUCN setiap spesies komoditi di pasar penggir papas didata berdasarkan data untuk memberikan gambaran kategori konservasi tiap spesies. Data IUCN yang digunakan mengacu kepada daftar di The IUCN Red List of Threatened Species.

\section{HASIL DAN PEMBAHASAN \\ Detail Demografi dari Informan}

Informan dalam penelitian ini memiliki latar belakang yang berbeda-beda. Latar belakang yang dimaksud adalah tingkat pendidikan terakhir, gender, suku, dan umur. Keseluruhan informan berjumlah 45 yang dibagi menjadi 3 kelompok (nelayan, distributor/penadah, dan pembeli), di mana pada setiap kelompok diwakili oleh 15 orang informan. Rincian latar belakang informan dalam penelitian ini dapat dilihat pada tabel 1. 
Tabel 1. Detail Demografi Keseluruhan Informan

\begin{tabular}{lcccccc}
\hline \multicolumn{1}{c}{ Demografi } & \multicolumn{2}{c}{ Nelayan } & \multicolumn{2}{c}{ Penadah } & \multicolumn{2}{c}{ Pembeli } \\
& Jumlah & (\%) & Jumlah & (\%) & Jumlah & (\%) \\
\hline Gender & & & & & & \\
- Laki-Laki & 15 & $100 \%$ & 10 & $66,67 \%$ & 0 & $0 \%$ \\
- Perempuan & 0 & $0 \%$ & 5 & $33,33 \%$ & 15 & $100 \%$ \\
$\begin{array}{l}\text { Pendidikan Terakhir } \\
\text { - Tidak Sekolah }\end{array}$ & 10 & $66,67 \%$ & 1 & $6,67 \%$ & 0 & $0 \%$ \\
- SD & 1 & $6,67 \%$ & 1 & $6,67 \%$ & 1 & $6,67 \%$ \\
- SMP & 2 & $13,33 \%$ & 8 & $53,33 \%$ & 7 & $46,67 \%$ \\
- SMA & 2 & $13,33 \%$ & 5 & $33,33 \%$ & 2 & $13,33 \%$ \\
- S-1 & 0 & $0 \%$ & 0 & $0 \%$ & 5 & $33,33 \%$ \\
Suku & & & & & & \\
- Madura & 15 & $100 \%$ & 11 & $73,33 \%$ & 9 & $60 \%$ \\
- Jawa & 0 & $0 \%$ & 4 & $26,67 \%$ & 6 & $40 \%$ \\
Umur & & & & & & \\
- 20-30 & 0 & $0 \%$ & 0 & $0 \%$ & 2 & $13,33 \%$ \\
- 31-40 & 0 & $0 \%$ & 9 & $60 \%$ & 5 & $33,33 \%$ \\
- $\quad 41-50$ & 15 & $100 \%$ & 1 & $6,67 \%$ & 3 & $13,33 \%$ \\
- 51-60 & 0 & $0 \%$ & 5 & $33,33 \%$ & 5 & $33,33 \%$ \\
\hline
\end{tabular}

\section{Data Jenis Spesies Komoditi di Pasar Penggir Papas}

Berdasarkan pengumpulan data pada pasar penggir papas pada 3 kecamatan di Sumenep didapatkan sebanyak 24 spesies yang menjadi komoditi dalam proses jual beli, daftar nama spesies, dan manfaatnya dijabarkan pada tabel 2 .

Berdasarkan daftar jenis tersebut, dikelompokkan menjadi 2 kelompok, yaitu kelompok Protista mirip tumbuhan dan hewan, dan selanjutnya dibagi menjadi beberapa famili (suku) yang dijabarkan pada gambar 4. Berdasarkan grafik pada gambar 4 didapatkan data bahwa kingdom (kerajaan) terbanyak yang digunakan sebagai spesies komoditi di pasar penggir papas adalah kingdom animalia (hewan) sebanyak 88\%, dan sisanya kingdom Protista sebanyak 22\%.

Tingginya pemanfaatan hewan terutama dalam superkelas Pisces (ikan) pada pasarpenggir papas, karena ikan merupakan salah satu komoditi baik dimanfaatkan oleh masyarakat, maupun komoditi ekspor (Philips et al., 2016). Ikan juga dapat diolah menjadi berbagai jenis masakan atau dijual dalam keadaan segar. Berdasarkan data dari Kementerian Kelautan dan Perikanan (2018) total produksi perikanan di Indonesia dengan angka sementara sampai November 2017 sebesar 23,26 juta ton. Angka tersebut dirinci sebanyak 6,04 juta ton perikanan tangkap, dan 17,22 juta ton perikanan budidaya. Pada pasar penggir papas kebanyakan merupakan ikan hasil tangkap nelayan lokal dan sangat jarang hasil budidaya perikanan.

Komoditi hewan terbesar kedua adalah moluska, yang terdiri dari bivalvia (kerang) dan cephalopoda (cumi). Dua jenis moluska ini juga sangat banyak dijadikan komoditi oleh masyarakat di pasar penggir papas. Bivalvia dan Cephalopoda memegang peranan penting dalam komoditi karena banyaknya jenis masakan khususnya masakan tradisional maupun modern yang menggunakan bahan bakunya. Selain itu kedua komoditi ini memiliki kandungan gizi yang baik dan persentase bagian tubuhnya yang dapat dikonsumsi mencapai 80\% (untuk Cephalopoda) (Sudjoko, 1988). 
Tabel 2. Spesies Komoditi pada Pasar Penggir Papas

\begin{tabular}{|c|c|c|c|c|}
\hline No & Jenis (spesies) & $\begin{array}{l}\text { Nama } \\
\text { Lokal }\end{array}$ & $\begin{array}{l}\text { Bagian yang } \\
\text { digunakan }\end{array}$ & Manfaat \\
\hline 1 & Katsuwonus pelamisL. & Cakalan & Semua bagian & $\begin{array}{l}\text { Bahan pangan diolah dalam } \\
\text { berbagai sajian masakan }\end{array}$ \\
\hline 2 & $\begin{array}{l}\text { Sphyrna lewini Grifftih \& } \\
\text { Smith. }\end{array}$ & Mongseng & Semua bagian & $\begin{array}{l}\text { Bahan pangan diolah dalam } \\
\text { berbagai sajian masakan }\end{array}$ \\
\hline 3 & Caranx kurraG. Cuvier. & Lajang & Semua bagian & $\begin{array}{l}\text { Umumnya dipindang, sebelum } \\
\text { diolah menjadi masakan }\end{array}$ \\
\hline 4 & Euthynnus affinisCantor. & Tongkol & Semua bagian & $\begin{array}{l}\text { Bahan pangan diolah dalam } \\
\text { berbagai sajian masakan }\end{array}$ \\
\hline 5 & $\begin{array}{l}\text { Thunnus } \\
\text { albacaresBonnaterre. }\end{array}$ & Madidihang & Semua bagian & $\begin{array}{l}\text { Bahan pangan, dan sebagai bahan } \\
\text { baku pembuatan petis ikan }\end{array}$ \\
\hline 6 & $\begin{array}{l}\text { Scomberomorus } \\
\text { commerson Lacépède. }\end{array}$ & Tenggiri & Semua bagian & $\begin{array}{l}\text { Bahan pangan, dan sebagai bahan } \\
\text { baku pembuatan petis ikan }\end{array}$ \\
\hline 7 & $\begin{array}{l}\text { Sardinella } \\
\text { lemuruBleeker. }\end{array}$ & Lemuru & Semua bagian & $\begin{array}{l}\text { Umumnya dipindang, sebelum } \\
\text { diolah menjadi masakan }\end{array}$ \\
\hline 8 & $\begin{array}{l}\text { Rastrelliger } \\
\text { faughniMatsui. }\end{array}$ & kembung & Semua bagian & $\begin{array}{l}\text { Umumnya dipindang, sebelum } \\
\text { diolah menjadi masakan }\end{array}$ \\
\hline 9 & Engraulis sp, & Kenduy & Semua bagian & $\begin{array}{l}\text { Bahan pangan diolah dalam } \\
\text { berbagai sajian masakan }\end{array}$ \\
\hline 10 & $\begin{array}{l}\text { Carcharhinus leucas } \\
\text { Muller \& Henle }\end{array}$ & Mondung & Semua bagian & $\begin{array}{l}\text { Bahan pangan diolah dalam } \\
\text { berbagai sajian masakan }\end{array}$ \\
\hline 11 & Makaira indica Cuvier & Talang & Semua bagian & $\begin{array}{l}\text { Bahan pangan diolah dalam } \\
\text { berbagai sajian masakan }\end{array}$ \\
\hline 12 & Anadara granosaL. & $\begin{array}{l}\text { Kerrang } \\
\text { dara }\end{array}$ & Daging & $\begin{array}{l}\text { Bahan pangan, diolah dalam } \\
\text { berbagai sajian }\end{array}$ \\
\hline 13 & $\begin{array}{l}\text { Polymesoda erosac } \\
\text { Solander. }\end{array}$ & Kepah & $\begin{array}{l}\text { Cangkang } \\
\text { Daging } \\
\text { Cangkang }\end{array}$ & $\begin{array}{l}\text { Bahan kerajinan tangan } \\
\text { Bahan pangan, diolah dalam } \\
\text { berbagai sajian } \\
\text { Bahan kerajinan tangan }\end{array}$ \\
\hline 14 & Meretrix meretrix L. & $\begin{array}{l}\text { Kerrang } \\
\text { tahu }\end{array}$ & $\begin{array}{l}\text { Daging } \\
\text { Cangkang }\end{array}$ & $\begin{array}{l}\text { Bahan pangan, diolah dalam } \\
\text { berbagai sajian } \\
\text { Bahan kerajinan tangan }\end{array}$ \\
\hline 15 & Crassostrea sp. & Terem & Daging & $\begin{array}{l}\text { Bahan pangan, dan sebagai } \\
\text { bahan pembuatan saus }\end{array}$ \\
\hline 16 & Solen vaginalisDesh. & Lorjuk & $\begin{array}{l}\text { Cangkang } \\
\text { Daging }\end{array}$ & $\begin{array}{l}\text { Bahan kerajinan tangan } \\
\text { Campuran rengginang }\end{array}$ \\
\hline 17 & Loligo pealeii Lesueur. & Ennos & Daging & $\begin{array}{l}\text { Bahan pangan, umumnya } \\
\text { disajikan dalam bentuk makanan } \\
\text { berkuah }\end{array}$ \\
\hline 18 & Corbula FabaHinds. & Te-rete & Daging & $\begin{array}{l}\text { Bahan tambahan/ campuran } \\
\text { dalam berbagai olahan seafood }\end{array}$ \\
\hline 19 & Scylla spp. & Kopeteng & $\begin{array}{l}\text { Daging } \\
\text { Cangkang }\end{array}$ & $\begin{array}{l}\text { Bahan pangan } \\
\text { Campuran pupuk }\end{array}$ \\
\hline 20 & Portunus pelagicusL. & Rajungan & $\begin{array}{l}\text { Daging } \\
\text { Cangkang }\end{array}$ & $\begin{array}{l}\text { Bahan pangan } \\
\text { Campuran pupuk }\end{array}$ \\
\hline 21 & $\begin{array}{l}\text { Litopenaeus } \\
\text { vannameiBoone }\end{array}$ & Odeng & $\begin{array}{l}\text { Daging } \\
\text { Kulit }\end{array}$ & $\begin{array}{l}\text { Bahan Pangan } \\
\text { Campuran pupuk }\end{array}$ \\
\hline 22 & $\begin{array}{l}\text { Eucheuma } \\
\text { spinosum J.Agardh }\end{array}$ & Bulung & Semua bagian & $\begin{array}{l}\text { Diolah sebagai agar-agar, atau } \\
\text { dicampur langsung ke dalam } \\
\text { minuman }\end{array}$ \\
\hline 23 & $\begin{array}{l}\text { Eucheuma } \\
\text { cottoniiWeber-van Bosse }\end{array}$ & Bulung & Semua bagian & $\begin{array}{l}\text { Diolah sebagai agar-agar, atau } \\
\text { dicampur langsung ke dalam } \\
\text { minuman }\end{array}$ \\
\hline 24 & Hypnea sp. & Bulung & Semua bagian & $\begin{array}{l}\text { Diolah sebagai agar-agar, atau } \\
\text { dicampur ke dalam minuman }\end{array}$ \\
\hline
\end{tabular}


Berdasarkan persentase spesies komoditi yang di temukan di pasar penggir jumlah terbanyak kedua merupakan protista mirip tumbuhan. Spesies yang temukan merupakan famili (suku) Cystocloniaceae (62\%), dan Solieriaceae (38\%). Kedua famili ini merupakan alga. Indonesia merupakan salah satu negara dengan tingkat komoditi alga terbesar. Alga juga merupakan salah satu komoditi yang memiliki nilai ekonomis tinggi karena perannya banyak digunakan dalam kehidupan sehari-hari, khususnya sebagai salah satu bahan pangan. Salim dan Ernawati (2015) menyatakan bahwa alga memiliki nilai gizi yang sangat baik sehingga merupakan salah satu komoditi potensial yang bisa dikembangkan di Indonesia. Valderrama et al., (2013) juga menyatakan alga dapat dimanfatkan dalam banyak hal seperti sumber makanan langsung bagi manusia, pakan ternak, bahan baku pupuk dan bahan baku industri. Berdasarkan data dari KKP (2013) saat ini Indoensia merupakan negara memanfaatkan 384.700 Ha lahan yang digunakan dalam penanaman alga.

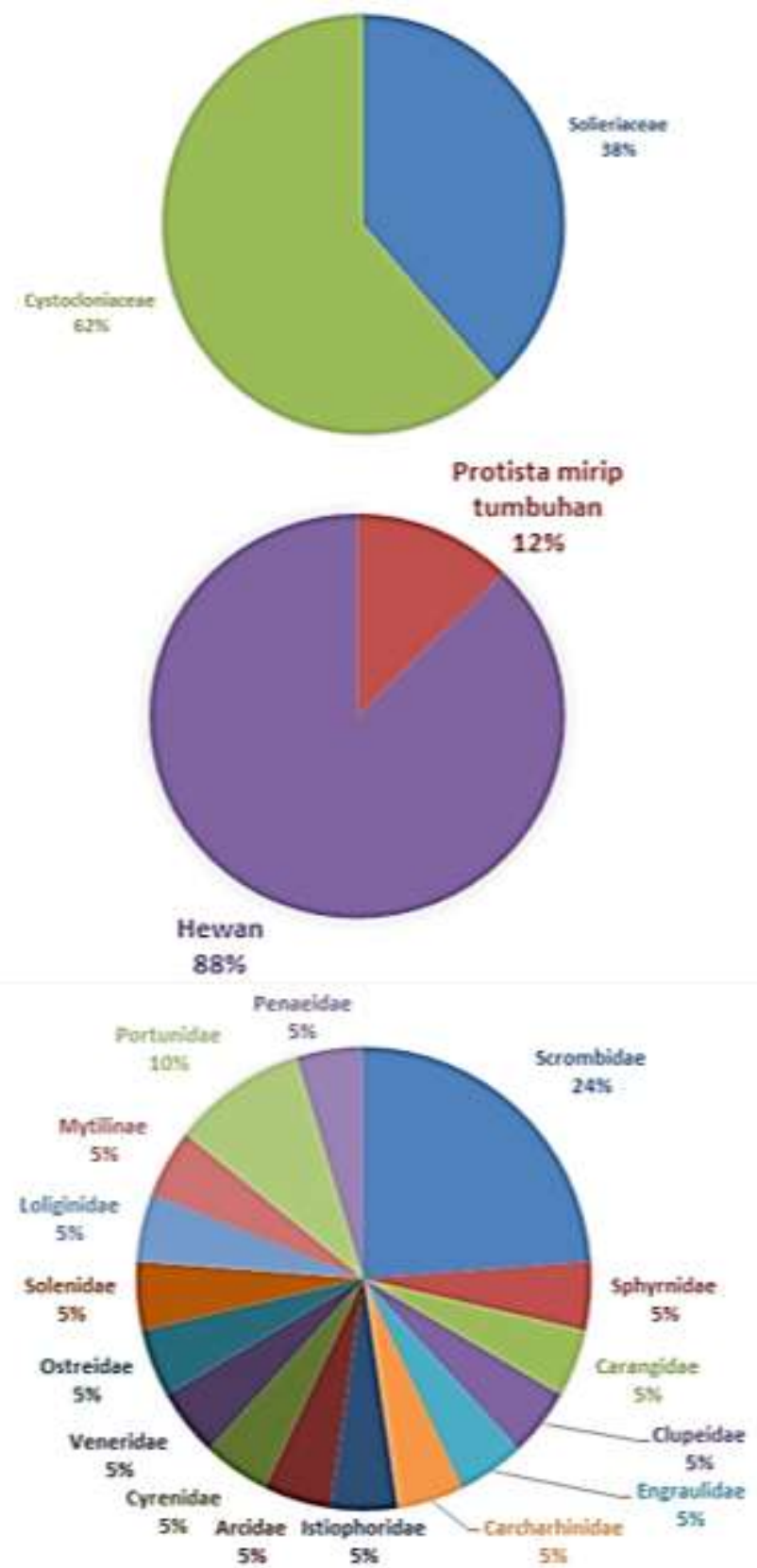

Gambar 4. Persentase Spesies Komoditi di Pasar Penggir Papas 


\section{Nilai RFC, FL dan Status IUCN}

Setiap spesies komoditi di pasar penggir papas memiliki variasi tingkat kepentingan dan kesukaan di masyarakat. Berdasarkan hal tersebut maka perlu dilakukan pendataan terkait frekuensi sitasi relative (relative frequency of citation) dan tingkat kesetiaan/ kesukaan (fidelity level) untuk mengetahui tingkat kepentingan dan kesukaan masyarakat. Nilai RFC dan FL disajikan pada tabel 3. Selain itu pada tabel 3 juga didata terkait status IUCN setiap spesies komoditi.

Tabel 3. Nilai RFC, FL dan Status IUCN Spesies Komoditi Pasar Penggir Papas

\begin{tabular}{llccl}
\hline No & \multicolumn{1}{c}{ Jenis (spesies) } & RFC & FL & Status IUCN \\
\hline 1 & Katsuwonus pelamisL. & 1 & $95.55 \%$ & Least Concern \\
2 & Sphyrna lewini Grifftih \& Smith. & 0.11 & $6.67 \%$ & Endangered \\
3 & Caranx kurraG. Cuvier. & 0.89 & $93.33 \%$ & Not Evaluated \\
4 & Euthynnus affinisCantor. & 0.95 & $97.78 \%$ & Least Concern \\
5 & Thunnus albacaresBonnaterre. & 0.33 & $55.55 \%$ & Near Threatened \\
6 & Scomberomorus commerson Lacépède & 0.67 & $66.67 \%$ & Near Threatened \\
7 & Sardinella lemuruBleeker. & 0.22 & $24.44 \%$ & Not Evaluated \\
8 & Rastrelliger faughniMatsui. & 0.73 & $66.67 \%$ & Data Deficient \\
9 & Engraulis sp, & 0.91 & $100 \%$ & Data Deficient \\
10 & Carcharhinus leucas Müller \& Henle. & 0.13 & $11.11 \%$ & Near Threatened \\
11 & Makaira indica Cuvier & 0.07 & $33.33 \%$ & Data Deficient \\
12 & Anadara granosaL. & 0.82 & $77.78 \%$ & Not Evaluated \\
13 & Polymesoda erosa Solander. & 0.87 & $82.22 \%$ & Not Evaluated \\
14 & Meretrix meretrixL. & 0.71 & $80.00 \%$ & Not Evaluated \\
15 & Crassostrea sp. & 0.64 & $71.11 \%$ & Not Evaluated \\
16 & Solen vaginalisDesh. & 0.51 & $46.67 \%$ & Not Evaluated \\
17 & Loligo pealeii Lesueur. & 0.69 & $66.67 \%$ & Not Evaluated \\
18 & Corbula FabaHinds. & 0.42 & $33.33 \%$ & Not Evaluated \\
19 & Scylla spp. & 0.91 & $88.89 \%$ & Not Evaluated \\
20 & Portunus pelagicusL. & 0.91 & $91.11 \%$ & Not Evaluated \\
21 & Litopenaeus vannameiBoone. & 0.91 & $93.33 \%$ & Not Evaluated \\
22 & Eucheuma spinosum J.Agardh & 0.89 & $82.22 \%$ & Not Evaluated \\
23 & Eucheuma cottoniiWeber-van Bosse & 0.89 & $80.00 \%$ & Not Evaluated \\
24 & Hypnea sp. & 0.67 & $68.89 \%$ & Not Evaluated \\
\hline
\end{tabular}

Berdasarkan data RFC dan FL, kemudian disusun scatter diagram (diagram pencar) untuk mengetahui hubungan RFC dan FL (Gambar 5). Berdasarkan pola hubungan ini, maka dibagi menjadi 4 kelompok, yaitu: kepentingan rendah dan kesukaan rendah (kelompok I), kepentingan tinggi dan kesukaan rendah (kelompok II), kepentingan rendah dan kesukaan tinggi (kelompok III), dan kepentingan tinggi dan kesukaan tinggi (kelompok IV).

Berdasarkan data pada diagram pencar terdapat 5 spesies pada kelompok I, 1 spesies pada kelompok 2, 1 spesies pada kelompok 3 dan 17 spesies pada kelompok IV. Berdasarkan hal ini, kebanyakan spesies komoditi pada jual beli pasar penggir papas memiliki tingkat kepentingan dan kesukaan yang tinggi. Hasil wawancara menunjukkan bahwa pada spesies yang masuk ke dalam kelompok I, II dan III umumnya bukan merupakan komoditi yang sering diperjualbelikan setiap hari dan hanya ada pada momen atau acara tertentu. 


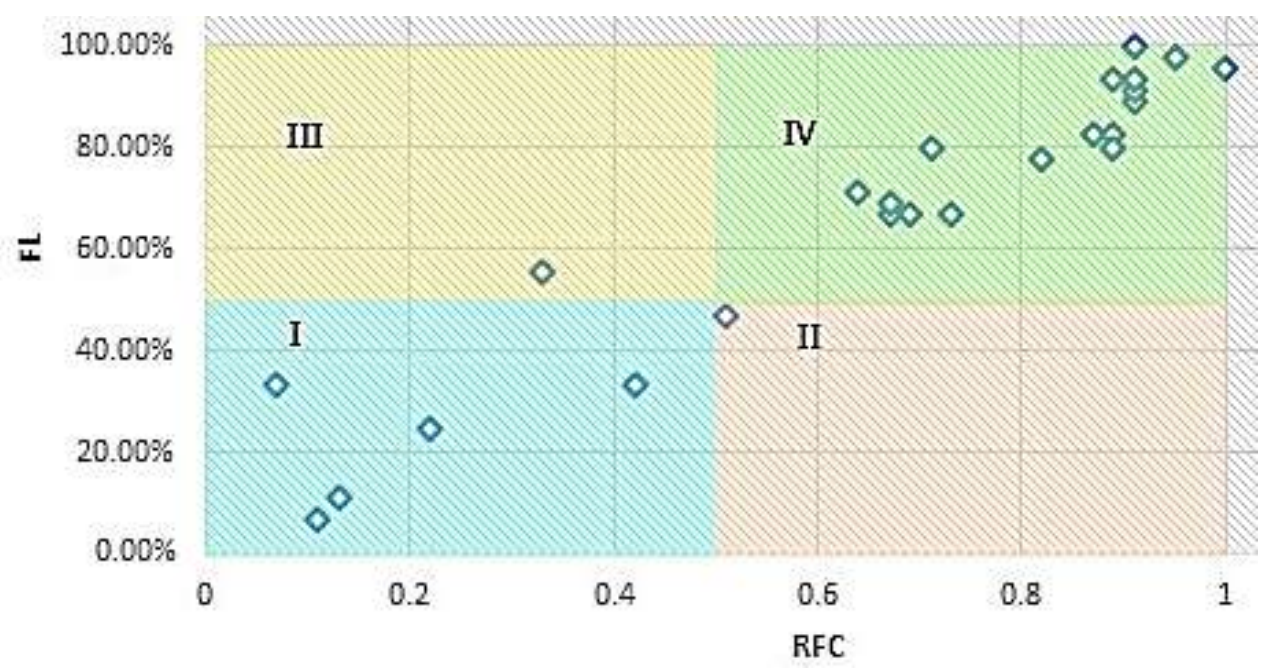

Gambar 5. Scatter Diagram untuk Perbandingan FL dan RFC pada spesies komoditi di Pasar Penggir Papas

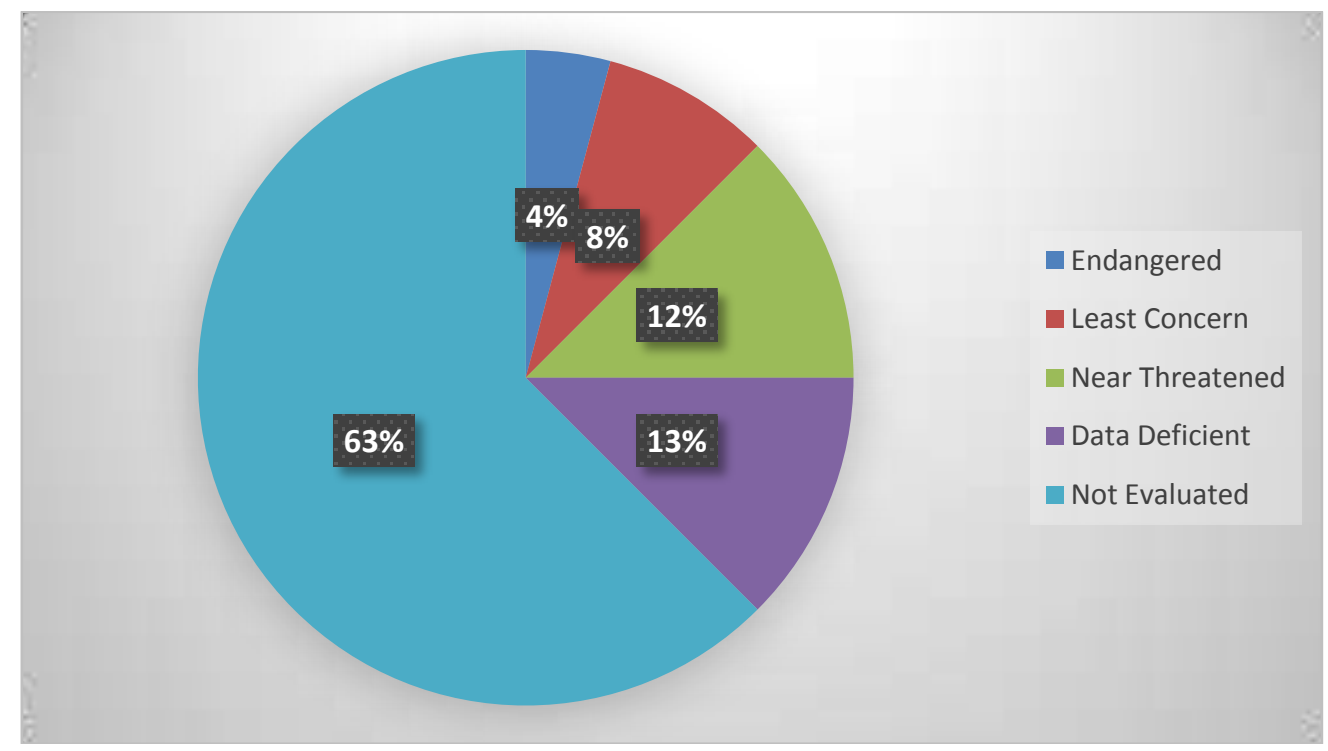

Gambar 6. Persentase Status IUCN Spesies Komoditi di Pasar Penggir Papas

Data terkait status IUCN pada Gambar 6, setidaknya terdapat 63\% spesies yang belum terevaluasi, sementara pada spesies yang diperjualbelikan terdapat sekitar 4\% yang termasuk daftar endangered yaitu Sphyrna lewini Grifftih \& Smith. Jual beli spesies yang termasuk daftar endangered karena nelayan maupun penadah masih belum mengetahui hal ini. Berdasarkan data lain spesies lainnya terdapat spesies yang hampir terancam (near threatened) sebesar 12\%. Spesies near threatened sangat perlu diawasi kegiatan jual belinya, karena berdasarkan data FL ada beberapa spesies yang sangat digemari oleh masyarakat sebagai bahan konsumsi, yaitu Thunnus albacares Bonnaterre (55.55\%) dan Scomberomorus commerson Lacépède (66.67\%). Spesies lainnya masih dalam batas aman untuk kegiatan konsumsi dan jual beli, pada kategori beresiko rendah (Least Concern) sebesar 8\% dan data deficient sebesar $13 \%$. 


\section{SIMPULAN}

Berdasarkan pengumpulan data terkait spesies komditi pada pasar penggir papas di daerah sumenep didapatkan sebanyak 24 spesies. Terdapat 5 spesies pada kelompok I (kepentingan rendah dan kesukaan rendah), 1 spesies pada kelompok II (kepentingan tinggi dan kesukaan rendah), 1 spesies pada kelompok III (kepentingan rendah dan kesukaan tinggi) dan 17 spesies pada kelompok IV (kepentingan tinggi dan kesukaan tinggi). Data terkait status IUCN setidaknya terdapat 63\% spesies yang belum terevaluasi, 4\% yang termasuk daftar terancam (endangered), 12\% hampir terancam (near threatened), 8\% beresiko rendah (least concern) dan 13\% data kurang (data deficient).

\section{REFERENSI}

Alexiandes, M.N. (1996). Selected Guidelines for Ethnobotanical Research: a Dield Manual. In : Advances in Economic Botany Volume 10. Bronx : The New York Botanical Garden : Bronx

BAPPEDA JATIM (2013). Potensi dan Produk Unggulan Jawa Timur (online). http://bappeda.jatimprov.go.id. Diakses 5 Mei 2018

Borah, M.P. \& Prasad, S. (2017). Ethnozoological study of animals based medicine used by traditional healers and indigenous inhabitants in the adjoining areas of Gibbon Wildlife Sanctuary, Assam, India. Journal of Ethnobiology and Ethnomedicine, 13(1) : 1-13

Durand, S.S. (2010). Studi Potensi Sumberdaya Alam di Kawasan Pesisir Kabupaten Minahasa Selatan. Jurnal Perikanan dan Kelautan 4 (1) : 1-7

Friedmen, J., Yaniv, Z., Dafni, A., \& Palewitch, D. (1986). A Preliminary Classification of the Healing Potential of Medicinal Plants, based on a Rational Analysis of anEthnopharmocological Field Survey among Bedouins in the Negev Desert.Israel. J Ethnopharmacol, 16:275-278

Huntington, H.P. (2000). Using Traditonal Ecological Knowledge in Science: Methods and Applications. Ecol Appl 10 : 1270-1274

Kementerian Kelautan \& Perikanan (KKP). (2013). Buku Saku: Informasi Rumput Laut. Direktorat Usaha dan Investasi Direktorat Jenderal Pengolahan dan Pemasaran Hasil Perikanan.

Kementerian Kelautan \& Perikanan (2018). Produktifitas Perikanan Indonesia. Forum Merdeka Barat 9 : Jakarta

Kim, H \& Song, M.J. (2011). Analysis and Recording of Orally Transmitted Knowledge about Medicinal Plants in the Southern Mountainous Region of Korea. J. Ethnopharmacol 134 : 676-696

Long, C.L., Wang J.R., (1996). The Principle, Method and Application of Participatory Rural Assessment. Kunming: Yunnan Science and Technology Press

Martin, G.J. (2007). Ethnobotany - A methods Manual. London: Earthsacn

Mootsamy, A. \& Mahomoodly, M.F. (2014). A Quantitative Ethnozoological Asessment of Traditionally Used Animal based Therapies in the Tropical Island of Mauritius. J Ethnopharmacol 154 (3): 847-857

Nezon, E. (2011). Pengembangan dan Pengelolaan Konservasi Sumberdaya Ikan. Direktorat KOnservasi Kawasan dan Jenis Ikan. Jakarta : Direktorat Jenderal Kelautan Pesisir dan Pulau-Pulau Kecil. Kementerian Kelautan dan Perikanan 
Phillips, M., Henriksson, P.J.G., Tran, N., Chan, C.Y., Mohan, C.V., Rodriguez, U.P., Suri, S., Hal,l S. \& Koeshendrajana, S. (2016). Menjelajahi Masa Depan perikanan Budidaya Indonesia. Penang Malaysia: WorldFish Laporan Program

Salim, Z \& Ernawati. (2015). Info Komoditi Rumput Laut. Jakarta: Imprint Al-Mawardi Prima

Sudjoko, B (1988). Cumi-Cumi (Cephalopoda, Moluska) Sebagai Salah Satu Bahan Makanan dari Laut. Oseana 8(3) : 97 - 107

Theis,J., \& Grady, H.M.. (1991) Participatory Rural Appraisal for Community Development. London: International Institute for Environment and Development.

Ubaidillah, R., Marwoto, R.M., Hadiaty, R.K., Fahmi, Wowor, D., Mumpuni, Pratiwi, R., Tjakrawidja, A. H., Mujiono, Hartati, S.T., Heryanto, Riyanto, A., \& Mujiono, N. (2013). Biota Perairan Terancam Punah di Indonesia: Prioritas Perlindungan. Jakarta : Direktorat Konservasi Kawasan dan Jenis Ikan Ditjen Kelautan, Pesisir, dan Pulau-Pulau Kecil, Kementerian Kelautan dan Perikanan Bekerjasama dengan Lembaga Ilmu Pengetahuan Indonesia

Vitalini, S., Iriti, M., Puricelli, C., Ciuchi, D., Segale, A., \& Fico, G. (2012). Traditional Knowledge on Medicinal and Food Plantas used in Val san Giacomo (Sondrio, Italy) - An Alpine Ethnobotanical Study. J Ethnopharmacol 145 : 517-529

Valderrama, D., J.Cai., N. Hishamunda., \& N. Ridler. (2013). Social and economic dimensions of carrageenan seaweed farming. Fisheries and Aquaculture Technical Paper No. 580. Rome: FAO. 